
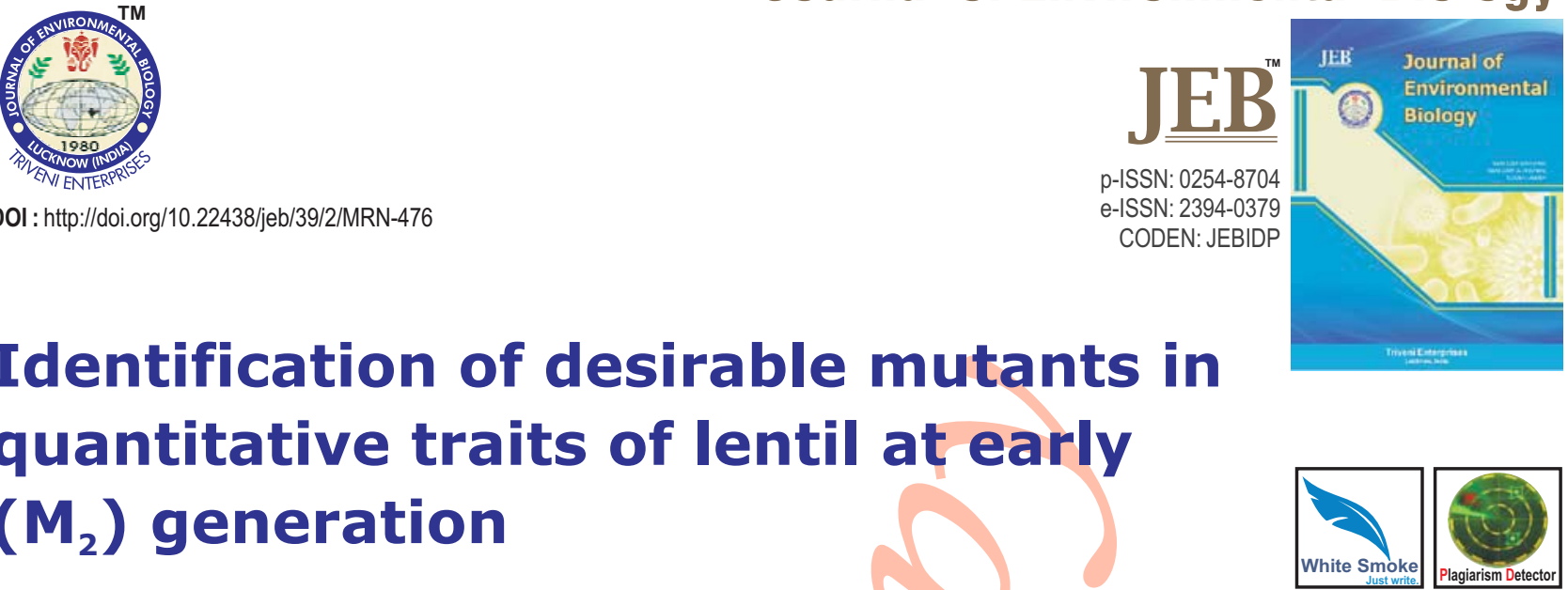

\title{
Identification of desirable mutants in quantitative traits of lentil at early $\left(M_{2}\right)$ generation
}

Authors Info

D. Tabti ${ }^{12 *}$, M. Laouar', K. Rajendran ${ }^{3}$, S. Kumar ${ }^{3}$ and $A$. Abdelguerfi'

'ENSA, Laboratoire d'Amélioration Intégrative des Productions Végétales, Alger, 16051, Algérie

${ }^{2}$ ENSA, Laboratoire des Ressources Génétiques et Biotechnologies, Alger, 16051, Algérie

${ }^{3}$ Biodiversity and Integrated Gene Management Program. The International Centre for Agricultural Research in Dry Areas, RabatInstitutes,10020, Morocco

*Corresponding Author Email : tdahbia1990@gmail.com

Key words

BLUPs values

Gamma rays

Lentil

Lethal dose

Mutants

Publication Info

Paper received : 05.10.2016

Revised received : 07.02 .2017

Re-revised received : 30.05 .2017

Accepted : 28.06 .2017

\section{Abstract}

Aim : Narrow genetic base and limited genetic diversity are the major research constraints that affect the efficacy of class breeding methods in lentil. In order to circumvent these conditions, mutation breeding techniques were successfully employed in many studies. The present study was conducted to find the $L D_{50}$ dose of gamma rays in lentil cultivar, Idlib-3 and also to develop and characterize $M_{2}$ population for economically important quantitative traits.

Methodology : Initially, seeds of lentil variety Idlib-3 were treated with eight doses $(45$, $60,75,90,100,200,300$ and $400 \mathrm{~Gy})$ of gamma rays. Germination percentage was recorded to determine $L_{50}$ by probit analysis. After determining $L D_{50}, M_{1}$ and $M_{2}$ generations were raised. At $M_{2}$ generation, mutant families were characterized for a set of ten different economically important traits.

Results : The $L_{50}$ of gamma rays was calculated as 104.34 Gy based on the germination percentage. In $\mathrm{M}_{2}$ generation many induced mutations such as chlorophyll mutation $(2.76 \%)$, stunted growth $(1.14 \%)$ and dwarf mutants $(0.35 \%)$ were recorded. Dunnett's test revealed a total of 13 superior families over parent for various quantitative
Gamma radiation treatment on lentil variety Idlib-3

traits. The results of Best Linear Unbiased Predictors (BLUPs) confirmed the recurrence and superiority of same seven families, identified in Dunnett's test for high seed yield.

Interpretation : Early selection in $\mathrm{M}_{2}$ generation was found useful to identify new desirable mutant traits in lentil. The superior families identified for early maturity, high yield and more total number of pods per plants could be either utilized as direct mutants or in the future crossing program. 


\section{Introduction}

Lentil (Lens culinaris Medik.subsp.culinaris) is one of the earliest domesticated crops in the Near East (Stefaniak and McPhee, 2015). It is an autogamous, diploid $(2 n=2 x=14)$ species with a genome size of approximately $4063 \mathrm{Mbp}$ (Arumuganathan and Earle, 1991). It is a drought tolerant legume crop. When compared to other food legumes it can be easily grown in marginal environments (Cubero, 1981). It is predominantly cultivated in the Indian subcontinent, the Middle East, Northern America, Southern Europe, and Eastern and Northern Africa for food (Gupta et al., 2011).

Lentil is the fourth most important food legume crop after faba bean, chickpea and peas in Algeria. Even-though, lentil cultivation is promoted by the Algerian Ministry of Agriculture, its production has decreased in the past few years (Riah et al., 2014; FAO, 2014) due to lack of adapted varieties to the agro-systems that have legumes production vocation. Moreover, attributes such as limited genetic diversity and narrow genetic base severely affect the crop improvement (Fratini et al., 2014). Research efforts are currently underway in many Algerian Agricultural Research Institutes to develop new lentil varieties for Algerian agro-climatic conditions.

Creating genetic variation through hybridization is a cumbersome practice in lentil. The small sized fragile flowers make the emasculation process difficult (Rana and Solanki, 2015). Moreover, self-fertile nature of the crop further imposes limitation to the success of the hybridization program. In view of that, classical plant breeding approaches have become slow and unreliable.

Alternatively, mutation breeding appears to play an important role in the genetic improvement of lentil. Mutants are usually induced by different types of chemical mutagens and ionizing radiations (Amin et al., 2015). Among them, gamma rays are commonly used mutagen to create variation in lentil (Singh et al., 2011). Gamma rays cause chromosomal rearrangements, deletions, and hence produce new source of genetic variations in plants (Bhat et al., 2007). The application of gamma rays is also found easy only on two steps: preparation of seeds and mutagen treatment (Toker et al., 2007). Gamma rays were successfully used to develop lentil cultivars such as Elista for resistance to main lentil diseases and Djudje for high protein content and good culinary quality (Tomlekova, 2010).

To avoid high level of mortality rate due to mutation, determination of safe dose at which half of the plant material survives, which is commonly known as Lethal Dose ${ }_{50}\left(\mathrm{LD}_{50}\right)$, should be estimated at initial stage. The $L D_{50}$ helps in determining the sensitivity of a particular variety to the critical dose of mutagen causing 50\% mortality rate (Kangarasu et al., 2014). It was reported that the factors such as seed size, maturity, hardiness, moisture content and time of the treatment influence variation in $\mathrm{LD}_{50}$ dose, even between different varieties of same crop (Karthika and Subba Lakshmi, 2006).
As mentioned in early mutation studies quantitative traits such as yield should undergo selection at early generation. Selections at early generation reduce the loss of desirable combination of favorable alleles (Solanki and Sharma, 2001, 2002; Sneep, 1977). It seems that exercise of selection is independent of the mutagen being used for the development of $\mathrm{M}_{2}$ population (Rana and Solanki, 2015). Moreover, in order to utilize the usefulness of mutations for efficient plant breeding, the study of frequency of chlorophyll mutants and viable mutants in $\mathrm{M}_{2}$ generation is widely recommended (Kharkwal, 2000).

With this background, the following study was conducted to determine the $L D_{50}$ dose of gamma rays in lentil cultivar, Idlib-3 and also to develop and characterize $M_{2}$ population for economically important quantitative traits.

\section{Materials and Methods}

All experiments were carried out at the National High School of Agriculture (ENSA), Algiers, Algeria during 2013-2015 cropping seasons. The experimental plot had sandy loam soil with a pH of 7.6 . It had $1.04 \%$ nitrogen, $11.69 \%$ organic matter and $0.06 \mathrm{ppm}$ available phosphorus. For this study, a microsperma type of lentil, Idlib-3 (ILL6994) derived from a cross between ILL99 (Moroccan landrace) and ILL5588 (Jordanian landrace) was employed.

Estimation of germination percentage : A total of 768 wellfilled, homogeneous, dry seeds ( $11 \%$ moisture) of ILL 6994 were chosen and divided into eight sets (96 seeds per set). Each of these eight sets were then exposed to 45,60,75, 90, 100, 200, 300 and 400 Gy gamma rays treatment using Cobalt $60\left({ }^{60} \mathrm{Co}\right)$ source in the gamma cell, National Center for Nuclear Research (CRNA), Algeria at the dose rate of $12.11 \mathrm{~Gy} \cdot \mathrm{min}^{-1}$. All eight sets of treated seeds along with a one set of untreated control seeds (96 seeds) were sown in pots (one plant per pot). On $25^{\text {th }}$ day after sowing, the total number of germinated seedlings were recorded across all treatments, as well as in the control. The germination percentage and the percentage over control were calculated according to the formula given by Kangarasu et al. (2014).

Raising $\mathrm{M}_{1}$ generation : In order to raise $\mathrm{M}_{1}$ generation, samples of 10,000 homogeneous, air-dried seeds of Idlib-3 were treated with $100 \mathrm{~Gy}$ gamma radiation. All treated as well as untreated seeds were sown in $600 \mathrm{~m}^{2}$ areas with $20 \mathrm{~cm} \times 10 \mathrm{~cm}$ spacing during 2013-14 cropping season. From this material, a total of 428 single plants were harvested and forwarded to raise $\mathrm{M}_{2}$ generation.

Raising $\mathrm{M}_{2}$ generation and data collection : From $\mathrm{M}_{1}$ (428 single plants), a sum of 140 single plants (4200 seeds), which had at least 30 seeds per plant were selected and sown $(40 \mathrm{~cm} \times 30 \mathrm{~cm}$ spacing) in a randomized complete block design with three replications during 2014-15 cropping season. All mutant progenies were characterized for viable mutants and chlorophyll mutants at different growth stages. The frequency of chlorophyll and viable mutations was calculated following the method of Khan and Tyagi 
(2009). Observations were recorded for a set of ten economically important traits namely, days to first flowering (DF), days to $95 \%$ maturity (DM), plant height (PH), height of first pod (HFP), number of primary branches (NPB), number of pods per peduncle (NPP), number of seeds per pod (NSP), total number of pods per plant (TPP), seed yield (SY) and hundred seed weight (HSW).

Statistical analysis : The $\mathrm{LD}_{50}$ value was calculated by probit analysis using SPSS software version 20 (IBM Corp., 2011). The probit vs log of the doses were plotted in a graph to fit a line of regression. From the plot of probit, the average dose response was calculated and the $L_{50}$ value was obtained (Heinrichs et al., 1981).

In order to identify mutant families which were significantly superior over the parent (untreated control) in $\mathrm{M}_{2}$, Dunnett's test was employed using Genstat software, version.18 (VSN International, 2015). The Best Linear Unbiased Prediction (BLUP) values were calculated (genotypes modeled as a random effect) for all quantitative characters and the twenty four superior mutant families over control for seed yield (SY) were selected. The BLUPs were calculated using IBP Breeding Management System Version 3.0.8 (2015).

\section{Results and Discussion}

Germination under different doses of gamma rays were recorded, and the percentage over control was calculated (Table 1). Germination was found to decrease progressively with the increasing dose of treatment. The highest germination percentage $(96.55 \%)$ was obtained at 45 Gy treatment and the lowest germination percentage was obtained at $400 \mathrm{~Gy}$ treatment $(4.6 \%)$. Similar results were observed by Solanki and Sharma (1994), Singh et al. (2007) in lentil and by Girjia and Dhanavel
Table 1 : Number of seeds germinated, germination percentage and percentage over control calculated for different doses of gamma ray treatment in lentil variety, Idlib-3

\begin{tabular}{llll}
\hline Dose (Gy) & $\begin{array}{l}\text { Number of seeds } \\
\text { germinated }\end{array}$ & $\begin{array}{l}\text { Germination } \\
\text { percentage }\end{array}$ & $\begin{array}{l}\text { Percentage } \\
\text { over control }\end{array}$ \\
\hline 0 & 87 & 90.62 & $100^{\mathrm{d}}$ \\
45 & 84 & 87.5 & $96.55^{\mathrm{d}}$ \\
60 & 75 & 78.12 & $86.21^{\mathrm{c}}$ \\
75 & 73 & 76.04 & $83.91^{\mathrm{c}}$ \\
90 & 71 & 73.96 & $81.61^{\mathrm{c}}$ \\
100 & 30 & 31.25 & $34.4^{\mathrm{b}}$ \\
200 & 9 & 9.37 & $10.34^{\mathrm{a}}$ \\
300 & 8 & 8.33 & $9.20^{\mathrm{a}}$ \\
400 & 4 & 4.16 & $4.60^{\mathrm{a}}$ \\
\hline \multicolumn{4}{c}{} \\
\hline
\end{tabular}

Means followed by same letter are not significantly different at $5 \%$ (Duncan Multiple range test)

(2009) in cowpea. Usually, the altered physiological balance caused by mutagenic treatments causes reduction in seed germination (Singh et al., 2007).

Based on the germination percentage and probits, $\mathrm{LD}_{50}$ of Idlib-3 was estimated. The $L_{50}$ value was obtained at $104.34 \mathrm{~Gy}$ gamma ray treatment $\left(R^{2}=0.92\right)$. Sharma and Sharma (1986) reported that the $L D_{50}$ of microsperma lentil types usually vary from 135 to 186 Gy. In $\mathrm{M}_{2}$ population, a significant reduction in survival of plants was observed at each growth stage. Even though only $95.88 \%$ seeds were germinated, $90.40 \%$ and $83.12 \%$ of seedlings survived at the stage of flowering and maturity respectively. It was further decreased to $37.29 \%$ and only a total of 1302 single plants (with seeds) were harvested at the end. These results indicate the

Table 2 : Mean performances of thirteen significantly superior mutants' families over parent, Idlib-3 identified by Dunett's test for ten traits

\begin{tabular}{lllllllllll}
\hline Families & DF & DM & PH $(\mathbf{c m})$ & HFP $(\mathbf{c m})$ & NPB & NPP & TPP & NSP & SY (g) & HSW $(\mathbf{g})$ \\
\hline 68 & 89.7 & $122.8^{* *}$ & 27.59 & 9.79 & 3.19 & 1.34 & 66.17 & 1.06 & 2.24 & 2.76 \\
70 & 87.97 & 123.5 & $\mathbf{3 0 . 5 ^ { * * }}$ & 11.12 & 2.98 & 1.41 & 75.01 & 1.06 & 2.18 & 3.23 \\
5 & 86.61 & 124.5 & $30.69^{* *}$ & 10.14 & 2.70 & 1.24 & 97.72 & 1.10 & $4.83^{* *}$ & 3.20 \\
11 & 89.17 & 127 & 25.54 & 9.18 & 2.48 & 1.27 & 31.37 & $1.11^{* *}$ & 2.14 & 2.6 \\
84 & 89.92 & 124.5 & 26.68 & 10.03 & 2.52 & 1.45 & 50.46 & $1.11^{* *}$ & 1.64 & 2.53 \\
118 & 90.38 & 125.6 & 26.49 & 9.73 & 2.52 & 1.54 & 37.71 & $1.12^{* *}$ & 1.196 & 2.29 \\
90 & 87.09 & 123.3 & 29.34 & 9.83 & 3.10 & 1.72 & $112.52^{* *}$ & 1.08 & $3.07^{* *}$ & 2.83 \\
33 & 88.74 & 126.5 & 24.01 & 9.28 & 2.25 & 0.97 & 18.53 & 1.007 & 0.62 & $3.78^{* *}$ \\
59 & 86.6 & 123 & 27.67 & 10.32 & 2.62 & 1.57 & 71.71 & 1.07 & $2.90^{* *}$ & 3.02 \\
75 & 89.66 & 126.7 & 27.79 & 10.29 & 2.25 & 1.35 & 40.44 & 1.06 & $2.91^{* *}$ & 2.91 \\
134 & 89.39 & 125.2 & 26.99 & 10.43 & 2.65 & 1.48 & 62.98 & 1.05 & $2.99^{* *}$ & 2.89 \\
133 & 90.01 & 125.6 & 26.9 & 10.26 & 2.82 & 1.52 & 58.27 & 1.07 & $3.84^{* *}$ & 3.14 \\
42 & 90.69 & 124.6 & 26.79 & 9.64 & 2.86 & 1.65 & 84.42 & 1.09 & $3.84^{* *}$ & 3.04 \\
Idlib-3 & 86.47 & 124.4 & 26.73 & 10.4 & 2.633 & 1.807 & 68.8 & 1.049 & 1.668 & 3.209 \\
SD & 1.505 & 1.368 & 1.797 & 0.505 & 0.283 & 0.215 & 25.85 & 0.0309 & 1.137 & 0.366 \\
SE $( \pm)$ & 0.402 & 0.366 & 0.480 & 0.135 & 0.0757 & 0.057 & 6.908 & 0.0082 & 0.304 & 0.0979 \\
\hline
\end{tabular}

**: significantly superior 
Table 3 : Identification of twenty four "best" mutant families, based on seed yield by BLUPS

\begin{tabular}{|c|c|c|c|c|c|c|c|c|c|c|}
\hline Families & DF & DM & $\mathrm{PH}(\mathrm{cm})$ & $\mathrm{HFP}(\mathrm{cm})$ & NPB & NPP & TPP & NSP & $S Y(g)$ & HSW (g) \\
\hline $5^{*}$ & 87.17 & 124.63 & 29.45 & 9.91 & 2.68 & 1.26 & 83.34 & 1.07 & 3.56 & 2.99 \\
\hline $42^{*}$ & 90.29 & 124.74 & 26.68 & 9.67 & 2.76 & 1.52 & 72.62 & 1.06 & 2.73 & 2.89 \\
\hline $90^{*}$ & 87.57 & 123.56 & 28.43 & 9.75 & 2.89 & 1.57 & 94.46 & 1.07 & 2.57 & 2.81 \\
\hline $133^{*}$ & 89.77 & 125.54 & 26.76 & 9.94 & 2.73 & 1.43 & 53.20 & 1.05 & 2.47 & 2.90 \\
\hline $59^{*}$ & 87.22 & 123.41 & 27.25 & 9.95 & 2.63 & 1.46 & 62.69 & 1.06 & 2.25 & 2.89 \\
\hline $134^{*}$ & 89.31 & 125.23 & 26.82 & 10.02 & 2.65 & 1.42 & 57.01 & 1.04 & 2.15 & 2.82 \\
\hline 80 & 89.32 & 123.55 & 26.73 & 10.14 & 2.67 & 1.52 & 62.29 & 1.03 & 2.03 & 2.98 \\
\hline 92 & 88.44 & 124.26 & 27.66 & 10.03 & 2.66 & 1.49 & 55.61 & 1.03 & 2.00 & 2.87 \\
\hline 82 & 88.09 & 123.99 & 26.60 & 10.53 & 2.77 & 1.33 & 53.06 & 1.04 & 1.92 & 2.91 \\
\hline $68^{*}$ & 89.56 & 123.15 & 27.25 & 9.74 & 2.94 & 1.32 & 59.96 & 1.05 & 1.91 & 2.77 \\
\hline $70^{*}$ & 88.21 & 123.75 & 29.32 & 10.39 & 2.83 & 1.38 & 66.48 & 1.08 & 1.90 & 3.04 \\
\hline 123 & 88.52 & 124.58 & 28.50 & 9.85 & 2.69 & 1.39 & 58.20 & 1.06 & 1.84 & 2.86 \\
\hline $75^{\star}$ & 89.52 & 126.52 & 27.37 & 9.97 & 2.43 & 1.33 & 40.23 & 1.04 & 1.80 & 2.81 \\
\hline 72 & 89.40 & 124.53 & 26.11 & 9.39 & 2.65 & 1.33 & 52.15 & 1.07 & 1.78 & 2.87 \\
\hline 137 & 87.93 & 124.89 & 27.91 & 9.79 & 2.65 & 1.32 & 52.19 & 1.08 & 1.76 & 2.70 \\
\hline 112 & 88.69 & 123.29 & 25.55 & 9.37 & 2.91 & 1.34 & 60.19 & 1.04 & 1.75 & 2.90 \\
\hline 10 & 87.75 & 124.76 & 28.75 & 10.63 & 2.82 & 1.40 & 52.07 & 1.05 & 1.75 & 2.94 \\
\hline 1 & 89.66 & 124.82 & 27.61 & 9.76 & 2.90 & 1.50 & 55.04 & 1.07 & 1.70 & 2.72 \\
\hline 129 & 88.26 & 123.26 & 27.51 & 10.13 & 2.62 & 1.45 & 61.22 & 1.03 & 1.68 & 2.98 \\
\hline 88 & 88.70 & 124.58 & 25.47 & 9.52 & 2.64 & 1.33 & 48.13 & 1.03 & 1.67 & 2.90 \\
\hline 30 & 89.39 & 124.94 & 25.80 & 9.61 & 2.71 & 1.42 & 44.77 & 1.05 & 1.66 & 2.83 \\
\hline 60 & 89.22 & 125.11 & 25.68 & 9.61 & 2.80 & 1.37 & 50.90 & 1.02 & 1.65 & 2.75 \\
\hline 50 & 88.14 & 124.82 & 27.32 & 10.28 & 2.63 & 1.42 & 50.42 & 1.02 & 1.63 & 2.80 \\
\hline 61 & 88.42 & 124.83 & 27.92 & 9.68 & 2.86 & 1.35 & 54.59 & 1.05 & 1.61 & 2.88 \\
\hline Idlib-3 & 87.05 & 124.52 & 26.66 & 10.04 & 2.64 & 1.64 & 62.31 & 1.04 & 1.57 & 3.07 \\
\hline
\end{tabular}

*: kept the same ranking as superior families; In bold are higher values of predicted mean compared to the control

deleterious effect of mutations on survival of plants over different growth stages. Arisha et al. (2015) noticed similar reduction in survival of $\mathrm{M}_{2}$ mutant plants at maturity stage in pepper.

The effectiveness of a given mutagen can be fully explicated through the frequency of induced mutations. Chlorophyll mutation frequency is a dependable index to evaluate the efficiency of mutagenic treatments, destined to generate a wide array of variability (Usharani and Kumar, 2015). In $\mathrm{M}_{2}$ generation, different types of chlorophyll mutants such as xantha, viridis and chlorina were observed in the present study. The frequency of chlorophyll mutation was found to be $2.76 \%$ (116 mutants). Sharma and Sharma (1981) recorded $2.55 \%$ and $1.26 \%$ chlorophyll mutants in macrosperma and microsperma lentils at 100 Gy. Similarly, Paul and Singh (2002) reported 0.8\% of chlorophyll mutants in microsperma lentils using 100 and 150 Gy. The frequency of chlorophyll mutation was observed as $1.21 \%$ and $2.42 \%$ in two varieties of soybean at $150 \mathrm{~Gy}$ (Khan and Tyagi, 2009). In cluster bean, Bhosle and Kothekar (2010) recorded $1.66 \%, 2.21 \%$ and $2.61 \%$ of chlorophyll mutations at 50 , 100 and 150 Gy, respectively.

The viable mutants observed in the present study consisted of forty eight stunted growth mutants (1.14\%), fifteen dwarf mutants $(0.35 \%)$, three mutants with four pods per peduncle $(0.07 \%)$ and three mutants with abnormal leaves $(0.07 \%)$. In previous studies, similar spectra of viable mutants were reported in $M_{2}$ population of chickpea (Kharkwal, 2000), cowpea (Girija and Dhanavel, 2009) and grasspea (Talukdar, 2009). Viable mutations are the result of gross chromosomal rearrangements caused by ionizing radiations and the application of different mutagens could alter the spectra of viable mutations (Ehrenberg etal., 1961).

In the present study, the superiority of mutant families over parent was studied through "comparison with control" (Dunnett's test). The total number of mutant families showing significant superiority over the parent varied from 1 to 7 for all traits. Only one family was found superior over the parent for days to maturity, total number of pods per plant and hundred seed weight; two families for plant height; three families for number of seeds per pod and seven families for seed yield. For other traits, no family was found superior over the parent. It appears that among the 140 evaluated mutant families; only 13 families $(0.09 \%)$ demonstrated superiority over the parent for yield and yield components, phenological and morphological characters (Table 2). Ali et al. (2010) found mutant lines which had superiority over parent for flowering, yield, number of branches and hundred seed weight in lentil. 
The Best Linear Unbiased Predictors (BLUPs) were more commonly utilized to increase the sugarcane breeding efficiency (Resende and Barbosa, 2006). It was found more effective method than routine phenotypic selection in walnut breeding (Aleta et al., 2004). However, there were no similar evidences found for legumes and other crops. In most of the fruit breeding programs (Imai et al., 2016), mutagenesis often accumulates highly unbalanced phenotypic records, which create serious obstacles for comparison and phenotypic selection. To overcome this obstacle, the best linear unbiased prediction (BLUP) method is widely recommended. In this study, the BLUP values were calculated for the set of ten economically important traits. A total of twenty four high yielding mutants were sorted out from the BLUP values. The range of BLUPs for seed yield varied from 1.61 to 3.56 g. The three best mutants families identified for seed yield also recorded high values for total number of pods per plant. Similarly, these high yielding families had demonstrated other desirable characters such as more plant height and early maturity. Nine families classified as best by Dunnett's test were also classified as the best ones by BLUP. It confirms again the superiority of mutants identified in the present study (Table 3).

The findings of the present study revealed some putative mutants of Idlib-3 at 100 Gy treatment in $\mathrm{M}_{2}$ generation which can be used as either direct mutants or in the future crossing program. However, it is recommended to have more number of individuals in $\mathrm{M}_{2}$ population to facilitate selection for seed yield, especially when $\mathrm{LD}_{50}$ is effective.

\section{Acknowledgments}

We thank Mr. M. Baaliouamer from Commissariat à I'Energie Atomique (COMENA) and Mr. R. Yefsah from Centre de Recherche Nucléaire d'Alger (CRNA) of Algeria for their research support.

\section{References}

Aleta, N., A. Ninot and J. Voltas: Retrospective evaluation of parental selection in nursery tests of Juglans regia L. using a mixed model analysis. Silvae Genet., 53, 26-33 (2004).

Ali, J.F., M.A. Arain and N.A. Shaikh: Genetic manipulation of lentil through induced mutations. Pak. J. Bot., 42, 3449-3455 (2010).

Amin, R., R.A. Laskar and S. Khan: Assessment of genetic response and character association for yield and yield components in lentil (Lens culinaris L.) population developed through chemical mutagenesis. Cogent Food Agricul., 1, 1-15 (2015).

Arisha, M.H., S.N.M. Shah, Z.H. Gong, H. J., C. Li and H.X. Zhang : Ethyl methane sulfonate induced mutations in $M_{2}$ generation and physiological variations in $\mathrm{M}_{1}$ generation of peppers (Capsicum annuum L.). Front. Plant Sci., 6, 399-409 (2015).

Arumuganathan, K. and E.D. Earle: Nuclear DNA content of some important plant species. Plant Mol. Biol. Rep., 9, 208-218 (1991).

Bhat, R.S, N.M. Upadhyaya, A. Chaudhury, C. Raghavan, F. Qiu, H. Wang, J. Wu, K. McNally, H. Leung and B. Till: Chemical and irradiation-induced mutants and Tilling. In: Rice Functional Genomics: Challenges, Progress and Prospects (Ed: N.M. Upadhyaya). Springer, New York, pp. 148-180 (2007).
Bhosle, S.S. and V.S. Kothekar: Mutagenic efficiency and effectiveness in cluster bean (Cyamopsis tetragonoloba (L.) Taub.). J. Phytol., 2, 21-27 (2010).

Cubero, J.I.: Origin, taxonomy and domestication. In: Lentil (Eds.: C. Webb and G. Hawtin). C.A.B., London, UK., pp. 15-38 (1981).

Ehrenberg, L., A. Gystafsson and U. Lundqvist: Viable mutants induced in barley by ionizing radiations and chemical mutagens. Hereditas, 47, 243-282 (1961).

Food and Agriculture Organization (FAO): crops statistics. Available at: http://www.fao.org/faostat/en/\#data/QC, (2014).

Fratini, R.M., M. Pérez de la Vega and M.L. Ruiz Sanchez: Lentil. In: Broadening the genetic base of grain legumes (Eds.: M. Singh, I.S. Bisht and M. Dutta). Springer, New Delhi, pp. 115-147 (2014).

Girija, M. and D. Dhanavel: Mutagenic effectiveness and efficiency of gamma rays, ethyl methane sulphonate and their combined treatments in cowpea (Vigna unguiculata L. Walp). Global J. Mol. Sci., 4, 68-75 (2009).

Gupta, D., R. Ford and P.W.J. Taylor: Lens. In: Wild crop relative: Genomic and Breeding Resources, Legume Crops and Forage (Ed.: C. Kole). Springer, Berlin and Heidelberg, pp. 127-139 (2011).

Heinrichs, E.A., S. Chelliah, S.L. Valencia, M.B. Arceo, L.T. Fabellar, G.B. Aquino and S. Pickin: Manual for testing insecticides on rice. International Rice Research Institute, Los Banos, Philippines (1981).

Imai, A., T. Kuniga, T. Yoshioka, K. Nonaka, N. Mitani, H. Fukamachi, N. Hiehata, M. Yamamoto and T. Hayashi: Evaluation of the best linear unbiased prediction method for breeding values of fruitquality traits in citrus. Tree Genet. Genom., 12, 119-129 (2016).

Kangarasu, S., S. Ganeshram and A. J. Joel: Determination of lethal dose for gamma rays and ethyl methane sulphonate induced mutagenesis in cassava (Manihot esculenta Crantz.). Int. J. Sci. Res., 3, 3-6 (2014).

Karthika, R. and B. Subba lakskmi : Effect of gamma rays and EMS on two varieties of soybean. Asian J. Plant Sci., 5, 721-724 (2006).

Khan, M.H. and S.D. Tyagi: Studies on induction of chlorophyll mutations in soybean, (Glycine max L. Merrill). Front. Agric. China, 3, 253258 (2009).

Kharkwal, M.C.: Induced mutations in chickpea (Cicer arietinum L.) IV. Types of macromutations induced. Indian J. Genet. Plant Breed., 60, 305-320 (2000).

Paul, A. and D.P. Singh: Induced chlorophyll mutations in lentil (Lens culinaris Medik). Indian J. Genet. Plant Breed., 6, 263-264 (2002).

Rana, A. and I.S. Solanki: Ethyl methane sulphonate induced genetic variability and heritability in macrosperma and microsperma lentils. J. Environ. Biol., 36, 1119-1123 (2015).

Resende, M.D.V.D. and M.H.P. Barbosa: Selection via simulated individual BLUP based on family genotypic effects in sugarcane. Pesq. Agropec. Bras., 41, 421-429 (2006).

Riah, N., G. Bénab, A. Djekoun, K. Heulin, P. de Lajudie and G. Laguerre: Genotypic and symbiotic diversity of Rhizobium populations associated with cultivated lentil and pea in sub-humid and semiarid regions of Eastern Algeria. System. Applied Microbiol., 37, 368-375(2014).

Sharma, S.K. and B. Sharma : Induced chlorophyll mutations in lentil. Indian J. Genet. Plant Breed., 41, 328-333 (1981).

Sharma, S.K. and B. Sharma: Mutagen sensitivity and mutability in lentil. Theoret. Appli. Genet., 71, 820-825 (1986).

Singh, M., S. Sardana and S.K. Sharma: Genetic resources of lentil and its utilization in India. Plant Genet. Res., 9, 30-37 (2011).

Singh, S.P., R.P. Singh, N.K. Singh, J.P. Prasad and J.P. Shahi: Mutagenic efficiency of gamma-rays, ethyl methane sulphonate 
and its combination on microsperma lentil (Lens culinaris Medik). Int. J.Agr. Sci., 3, 113-118 (2007).

Sneep, J.: Selection for yield in early generations of self-fertilizing crops. Euphytica, 26, 27-30 (1977).

Solanki, I.S. and B. Sharma: Mutagenic effectiveness and efficiency of gamma rays, ethylene imine and $\mathrm{N}$-nitroso-N-ethyl urea in macrosperma lentil (Lens culinaris Medik.). Indian J. Genet., 54, 72-76 (1994).

Solanki, I.S. and B. Sharma : Early generation selection of polygenic mutations in lentil (Lens culinaris Medik.). Indian J. Genet., 61, 330-334 (2001).

Solanki, I.S. and B. Sharma : Induced polygenic variability in different groups of mutagenic damage in lentil (Lens culinaris Medik.). Indian J. Genet., 62, 135-139 (2002).
Stefaniak, T.R. and K.E. McPhee: Lentil. In : Grain Legumes (Ed.: A.M. De Ron). Springer, New York, USA, pp. 111-140 (2015).

Talukdar, D.: Dwarf mutations in grass pea (Lathyrus sativus L.): Origin, morphology, inheritance and linkage studies. J. Genet., 88, 165175 (2009).

Toker, C., S.S. Yadav and I.S. Solanki: Mutation breeding. In: Lentil: An Ancient Crop for Modern Times (Eds.: S.S. Yadav, D.L McNeil and P.C. Stevenson). Springer, Netherlands, pp. 209-224 (2007).

Tomlekova, N.B.: Induced mutagenesis for crop improvement in Bulgaria. Plant Mut. Rep., 2, 4-27 (2010).

Usharani, K.S. and C.A. Kumar: Mutagenic effects of gamma rays and EMS on frequency and spectrum of chlorophyll mutations in urdbean (Vigna mungo (L.) Hepper). Indian J. Sci. Technol., 8, 927-933 (2015).

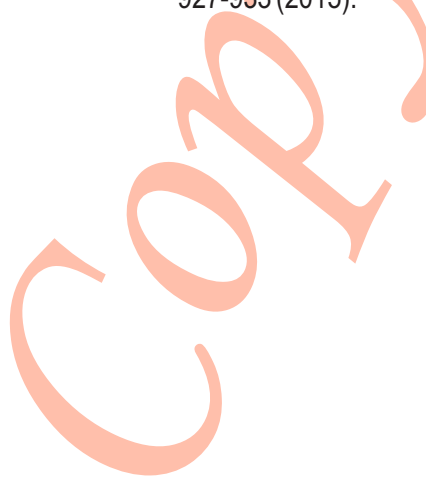

